\title{
TWO NEW NATURE RESERVES IN ENGLAND
}

\begin{abstract}
$T^{\mathrm{H}}$ HE Nature Conservancy has announced the establishment of the following two new nature reserves in England: Morden Bog, near Wareham, Dorsetshire; and Wren's Nest, Worcestershire.

Morden Bog reserve is about a mile north of Wareham and is close to the Conservancy's research station at Furzebrook. The northern part of the reserve consists of undulating heath and a small pine wood; in the drier parts there is considerable regeneration of Scots pine. In the south of the heath in a shallow lies Old Decoy Pond. The present declaration covers an area of 168 acres and has been made under a long lease from the Drax Estate. The Bog is a unique variant of southern heathland, and carries a rich flora and fauna, both vertebrate and invertebrate. It shares many characteristics with the heaths of Purbeck and the New Forest, including some of the rarities, for example, a grasshopper Chorthippus vagans and an ant Formica picea, which nests in sphagnum bog. 'Two of the insects-a digging, predatory wasp Pompilus rufus and an ant Formica pratensis - are not known to occur elsewhere in Britain. Morden Bog is the most interesting remnant of the great heaths which once stretched from Dorchester to Wareham and were described in Thomas Hardy's novels as "Egdon Heath". Freedom from disturbance and the most stringent precautions against fire are essential for the reserve. Access is by permit only, applications for which should be made to the Conservancy's Regional Officer for the South West at the Furzebrook Research Station, Wareham, Dorset.

The declaration of Wren's Nest as a nature reserve has been made possible by the co-operation of the local authority owning the land, the Dudley County Borough, and negotiations are almost completed with the Coseley Urban District Council for the addition
\end{abstract}

to the reserve of the northern part known locally as Mons Hill. Wren's Nest is internationally famous as a classical geological exposure of Upper Silurian rocks. The Wenlock Limestone (known also as the Dudley Limestone) has yielded a magnificent fossil fauna of probably well over three hundred species, all in a state of perfection such as no other locality in Britain exhibits. This includes the trilobites, shells, corals, sea-lilies and other marine life of the time that the strata were laid down in the sea, which is estimated to be some 330 million years ago. Fossils have been described and figured here since Dr. Plot's work of 1686. Specimens from Wren's Nest are preserved in museums all over the world, and there is a fine collection of them in the Dudley Public Library.

The area is a wooded hill with a broad flattened top (now playing fields) bounded by precipitous and deep artificial ravines which descend into great and steeply inclined caverns. The structure of the hill is a peculiar sharp anticline or arch of the rock strata, which, unlike most anticlines in Britain, can be seen to make a topographical feature. Similar structures are found concealed below ground, protruding into the Staffordshire Coalfield in the north, and Wren's Nest can help in assessing these features. The local limestone was largely won for the iron smelting of the nineteenth century and the early years of the present century. The ravines mark the surface workings, and the deep caverns record the underground exploitation, the limestone being removed by an underground canal which pierces the hill. The reserve is accessible to the public; but permission must be obtained to carry out scientific work, applications for which should be made to the Geologist at the Nature Conservancy headquarters, 19 Belgrave Square, London, S.W.1.

\section{SALT UPTAKE IN PLANTS}

T $\mathrm{HE}$ process of mineral salts uptake by plants is being investigated independently in several laboratories in Britain at the present time. It was appropriate, therefore, that it should be the subject of a session in Section $K$ (Botany) at the British Association meeting this year at Sheffield.

Opening the discussion, Dr. J. F. Sutcliffe (Department of Botany, King's College, London) emphasized the importance of a satisfactory knowledge of the salt relations of plant cells as a basis for an understanding of the processes of absorption and transport in intact rooted angiosperms. His contribution and that of Dr. A. B. Hope (present address : Botany School, Cambridge) were concerned with the mech. anism of salt uptake at the cellular level.

From the work of a number of investigators with various experimental materials the following view of salt absorption in a vacuolated plant cell has emerged.

There is an initial uptake of ions by diffusion and exchange through the cell wall and outer protoplasmic membrane into the bulk of the cytoplasm, where they are held by the establishment of Donnan equilibria and by adsorption on to protoplasmic constituents. This physical phase of uptake, which is limited in extent, does not depend directly on an expenditure of metabolic energy. Most of the ions taken into the cell are afterwards transferred across an inner membrane (the tonoplast) and accumulated in a free state in the vacuole. Since the tonoplast is rather impermeable to exchange and diffusion, and, moreover, since movement frequently occurs against a concentration gradient, it is evident that a supply of respiratory energy is involved.

It is generally agreed that active transport takes place by the operation of some form of a 'carrier' mechanism. This probably involves the formation of complexes between the ions and some organic constituents of the cell. These complexes move across the membrane and are broken down on the inner side to release the ions and re-form the original carrier molecules. Although a mechanism of this general kind, with suitable elaboration, will explain the facts that are known about salt accumulation, the precise details of the process have not yet been established. In particular, suitable carrier molecules have not yet been identified with certainty, and it 
is not clear how energy is incorporated into the system.

Against this background, Dr. Sutcliffe discussed various problems of salt accumulation presented by vacuolated cells of storage tissues. The development of an absorptive ability in cells of dormant organs under the influence of experimental treatments has been related to activation or synthesis of carrier molecules. Recent work of Dale and Sutcliffe (unpublished) has indicated that the inability of freshly cut slices of red beet root tissue to accumulate potassium ions from aqueous solutions of potassium chloride is caused indirectly by the non-functioning of a chloride-transporting mechanism rather than by lack of potassium carriers.

Non-growing cells of storage tissues have a limited ability to accumulate salts and, as uptake proceeds, the rate of absorption diminishes. Evidence has been obtained that this is associated with a decrease in the activity of the transport system rather than to an increase in the rate of outward movement of salt. It was suggested that the final stage in active transport is a spontaneous breakdown of the ion-carrier complex which proceeds so long as the free energy of the system is thereby diminished. With an increase of internal concentration, the complex breaks down less readily, until, when the tissue becomes saturated, all the carrier molecules remain in a combined form, and absorption ceases.

Cells of storage tissues possess the power of discrimination between different ions, and this ability has been examined with respect to the alkali metal ions. In terms of a carrier hypothesis, it is proposed that selective absorption depends on the preferential binding of certain ions by the transporting molecules. This property may prove useful in the ultimate isolation and identification of the substances involved, which is now to be attempted. Preliminary experiments have indicated that particulate fractions from red beet and potato tissues also bind some alkali cations in preference to others, and it seems possible that mitochondria may be a rich source of binding substances similar or identical to those responsible for ion transport in the plant cell.

Dr. Hope discussed fully the processes of physical uptake in vacuolated cells. He raised the question as to which structures in the cell determine the amount and rate of uptake of salts. The cell wall, outer cytoplasmic surface, bulk of the cytoplasm, cytoplasmic inclusions and the tonoplast were considered in turn. Some recent evidence from tracer studies with radioactive isotopes on beet and carrot tissue (Hope, unpublished) indicates the absence of a membrane resisting the exchange-diffusion of ions at the surface of the cytoplasm. It is considered likely that the cytoplasm acts as a Donnan phase with an immobile anion concentration of 100-300 m.equiv./l. The effects of the sign and valency of the supplied ions and the $p \mathrm{H}$ of the medium on the equilibrium concentration of ions in such a phase were discussed.

It has been established that some ions are bound in cell particles in a relatively non-exchangeable form. This may perhaps be associated with the presence of lipoprotein lamellæ which have been revealed by electron microscope studies. Physical uptake was estimated to account for about onehundredth of the total inward flux during active accumulation.

Dr. L. J. Middleton (Agricultural Research Council Field Station, Compton, Berks) read a paper on "Interactions in the Transport of Ions through Whole
Plants". He said that whercas in studies of salt uptake at the cellular level two phases are commonly distinguished, in intact plants a further process may be examined, namely, the passage of ions into the xylem. There have been some claims that salts may move passively into the conducting elements in the transpiration stream, but the bulk of transport appears to be under metabolic control.

In an experiment designed to discriminate between passive and active movement of salt into the xylem of young barley plants, use was made of the fact that ions are known to compete with one another in the physical and metabolic stages of uptake at the cellular level. Experimental work with disks of storage tissue has shown, for example, that strontium reduces the physical uptake of rubidium, but does not significantly depress the active absorption of these ions. In whole plants, the situation is apparently more complex since results are influenced by the salt status and transpiration-rate of the plant. It scems that salt content is a major factor controlling th $\theta$ gross number of ions absorbed, whereas transpirationrate is important only when the salt content of the plant is high.

The presence of strontium reduced both the uptake of rubidium and its transport into the shoot in high. salt plants, but had no significant effect in either case with low-salt plants. It was concluded that, in the latter, active secretion of rubidium into the xylem predominates, whereas in high-salt plants physical processes attain some importance.

Finally, Dr. J. L. Harley (Department of Botany, Oxford) spoke on "Factors affecting Salt Uptake by Beech Roots". He suggested that since explanations of the ecological distribution of plants often depend on views concerning their ability to absorb nutrients from the soil, the impact of physiological studies of salt uptake on ecology should be considered. As a phase in research, conditions not met in the field are frequently employed in laboratory work. Convenient temperatures, oxygen tensions and salt concentrations are used rather than ecologically probable conditions. Using results obtained with beech mycorrhizas sampled from natural habitats, the importance of laboratory work to field studies has been examined.

The effects of a range of temperature, oxygen tension and salt concentration on the uptake of various ions by beech mycorrhizas have been studied. High values of $Q_{10}$ were obtained for uptake over a temperature-range from near zero to $15^{\circ} \mathrm{C}$. For potassium concentrations expected in the soil an upper soil temperature of $20^{\circ} \mathrm{C}$. limits the condition in which beech mycorrhizas are effective absorbing organs.

Potassium is lost from mycorrhizal tissue into distilled water or dilute solutions containing salts when the oxygen tension falls below 3 per cent. The most efficient absorption of both anions and cations occurs in gaseous mixtures containing 10-20 per cent of oxygen. The oxygen concentration found in the soil horizons in which the roots grow naturally has not been observed to fall below 19 per cent by volume. It may be noted that beech is a plant of dry soils, intolerant of water-logged or heavy soils.

When salts were supplied at a high concentration $(10-100 \mathrm{mM})$ diffusion of ions through the tissues of the mycorrhiza was found to be an important phase in the process of absorption by the host. At low concentrations $(0 \cdot 1-1 \cdot 0 \mathrm{mM})$ diffusion of salts through the fungal tissue was negligible. Using a range of phosphate concentration and temperature, 